\title{
Erratum to: Laparoscopic repair of giant hiatus hernia: prosthesis is not required for successful outcome
}

Simon C. Gibson - Simon C. K. Wong •

Alice C. Dixon - Gregory L. Falk

Published online: 8 December 2012

(C) Springer Science+Business Media New York 2012

Erratum to: Surg Endosc

DOI 10.1007/s00464-012-2501-3

The correct spelling of the second author is Simon C.

K. Wong.

The online version of the original article can be found under doi:10.1007/s00464-012-2501-3.

S. C. Gibson ( () ) S. C. K. Wong · A. C. Dixon · G. L. Falk Concord Repatriation General Hospital, Concord, Sydney, NSW 2012, Australia

e-mail: simoncgibson@hotmail.com 